\title{
Adubação e o Período Anterior à Interferência das Plantas Daninhas na Cultura do Amendoim ${ }^{1}$
}

\author{
Effect of Fertilization on Weeds and on the Period before Weed Interference in the Peanut \\ Culture
}

YAMAUTI, M.S. ${ }^{2}$, ALVES, P.L.C.A. ${ }^{3}$, NEPOMUCENO, M. ${ }^{4}$ e MARTINS, J.V.F. ${ }^{5}$

\begin{abstract}
RESUMO - O presente trabalho teve como objetivo determinar o efeito da adubação sobre a comunidade infestante e sobre o período anterior à interferência (PAI) das plantas daninhas na cultura do amendoim, cv. IAC Runner 886, em sistema convencional. Os períodos de convivência estudados foram: $0,7,15,20,30,45,55$ e 126 dias após a emergência (DAE), totalizando oito tratamentos, dispostos em blocos casualizados, com quatro repetições, em dois niveis de adubação: 0 e $150 \mathrm{~kg} \mathrm{ha}^{-1}$ da formulação 00-20-20 (N-P-K). A adubação não alterou a composição da comunidade infestante, destacando-se Cyperus rotundus, Eleusine indica, Indigofera hirsuta, Portulaca oleraceae e Sida rhombifolia como as espécies de maior importância relativa. Contudo, a densidade de plantas daninhas foi maior na área não adubada, mas sem afetar de modo diferenciado a massa seca acumulada por elas. O cultivar de amendoim IAC Runner 886 pode conviver com essa comunidade com e sem adubação por até 15 e 17 DAE (PAI), respectivamente, sem sofrer perdas significativas na produção. A interferência das plantas daninhas reduziu entre 31 e 34\% a produtividade do amendoim para as áreas sem adubação e com adubação, respectivamente.
\end{abstract}

Palavras-chave: Arachis hypogaea, competição, fertilização, fitossociologia.

\begin{abstract}
This experiment was carried out to study the effect of fertilization on weed community and on the period before weed interference (PBI) in peanut culture, IAC Runner 886, under a conventional till system. The weed control periods studied were: $0,7,15,20,30,45,55$, and 126 days after emergence (DAE), totaling eight treatments, arranged in a randomized block design, with four replications and two levels of fertilization 10 and $150 \mathrm{~kg} \mathrm{ha} \mathrm{g}^{-1}$ of formulation 00-20-2O $(N-P-K))$. Fertilization did not affect the weed community, with the species Cyperus rotundus, Eleusine indica, Indigofera hirsuta, Portulaca oleracea and Sida rhombifolia being the most prominent at all levels of fertilization. However, weed density was higher in the non-fertilized area, but without particularly affecting the dry mass accumulated by these species. Peanut can grow along with the weed community, with and without fertilization, up to 15 and $17 D A E$, without significant yield losses. Weed interference reduced peanut productivity between 31 and 34\% for both the fertilized area and the area without fertilization, respectively.
\end{abstract}

Keywords: Arachis hypogaea, competition, fertilization, plant sociology.

\section{INTRODUÇÃO}

Um dos principais problemas da cultura de amendoim é a interferência causada pelas plantas daninhas (Everman et al., 2008), pois estas competem por luz, umidade e nutrientes (Ronchi et al., 2003) e influenciam no crescimento, no desenvolvimento e na produtividade

1 Recebido para publicação em 18.12.2009 e na forma revisada em 17.12.2010.

2 Doutoranda do Programa de Pós-Graduação em Produção Vegetal, Faculdade de Ciências Agrárias e Veterinárias, Universidade Estadual Paulista "Júlio Mesquita Filho" - FCAV/UNESP, Via de Acesso Prof. Paulo Donato Castellane s/n, 14884-900 JaboticabalSP, bolsista Fapesp, <micheliyamauti@yahoo.com.br>; ${ }^{3}$ Professor Adjunto, Dep. de Biologia Aplicada à Agropecuária, FCAV/UNESP, Jaboticabal-SP, <plalves@fcav.unesp.br>; ${ }^{4}$ Doutoranda do Programa de Pós-Graduação em Produção Vegetal, FCAV/UNESP, Jaboticabal-SP, bolsista Fapesp, <mariluce_n@hotmail.com>; 5 Técnico do Laboratório de Biologia e Manejo de Plantas Daninhas - DBAA, FCAV/UNESP, <martins@fcav.unesp.br> 
da cultura (Dias et al., 2009), podendo causar perdas de mais de $80 \%$, dependendo do cultivar e de outros fatores, como densidade da infestação, sua composição, fertilidade do solo, época do ano, por exemplo (Agostinho et al., 2006; Nepomuceno et al., 2007).

O grau de interferência depende de fatores ligados à comunidade infestante (composição específica, densidade e distribuição), à própria cultura (espécie ou clone, espaçamento e densidade de plantio) e à época e extensão do período de convivência. Depende também das condições edafoclimáticas e dos tratos culturais (Pitelli, 1985).

Os estudos que envolvem levantamentos fitossociológicos devem ser realizados em diferentes condições de fertilidade, uma vez que as comunidades infestantes podem variar sua composição florística em função do tipo e da intensidade de tratos culturais impostos, destacando-se que o reconhecimento das espécies presentes torna-se fundamental se for levado em conta o custo financeiro e ambiental da utilização de produtos químicos (Erasmo et al., 2004).

As determinações dos períodos de convivência tolerados por uma cultura com as plantas daninhas são obtidas estudando-se os períodos críticos de interferência (Pitelli, 1985). Em termos de manejo dessas plantas, o período anterior à interferência (PAI) tornase um dos períodos de maior importância do ciclo cultural, a partir do qual a produtividade é significativamente alterada (Meschede et al., 2004). Os resultados de pesquisa indicam grande variação nesses períodos para a cultura do amendoim, tanto para os de porte rasteiro como os ereto; o PAI pode variar de três a dez semanas (Pitelli et al., 1981, 1984; Barbosa \& Pitelli, 1990; Kasai et al., 1997; Agostinho et al., 2006; Nepomuceno et al. 2007; Everman et al., 2008; Dias et al., 2009).

Atualmente, existe a preocupação em estudar esses períodos associados a outros fatores que também alteram o grau de interferência das plantas daninhas, como, por exemplo, o cultivar utilizado (Agostinho et al., 2006), a sua época de semeadura (Nepomuceno et al., 2007) e o espaçamento entre linhas (Dias et al., 2009). Dentre esses fatores, deve-se destacar a importância da nutrição, pois as plantas competem pelos recursos no solo (Rizzardi et al., 2001). No caso das plantas daninhas, a extração de água e nutrientes reduz a disponibilidade desses recursos para as culturas, causando estresse e, consequentemente, perdas no rendimento da cultura (Rizzardi et al., 2001). Quando a cultura do amendoim for conduzida sem adubação, Quaggio \& Godoy (1997) recomendam dar preferência aos solos corrigidos por adubação de culturas anteriores, pois a cultura aproveita bem o efeito residual, sendo excelente para rotações, notadamente com a cana-de-açúcar. Nakagawa (2000) atribuiu ao fósforo maior contribuição para a maior produtividade da cultura.

Nesse contexto, pesquisas visando adquirir subsídios ao estabelecimento de estratégias para o fornecimento de nutrientes que favoreçam as culturas em detrimento das plantas daninhas, bem como conhecer o comportamento ou exigência nutricional da cultura quando sob competição com as plantas daninhas, mostram-se necessárias. Assim, o objetivo deste estudo foi avaliar o efeito da adubação sobre a comunidade infestante e sobre o período anterior à interferência das plantas daninhas na cultura do amendoimrasteiro, cultivar IAC Runner 886.

\section{MATERIAL E MÉTODOS}

Esta pesquisa constou de dois experimentos, instalados e conduzidos no mesmo talhão em novembro de 2007, durante a safra agrícola 2007/2008, em área experimental pertencente à Faculdade de Ciências Agrárias e Veterinárias da Universidade Estadual Paulista UNESP, localizada no municipio de Jaboticabal$\mathrm{SP}$, que se encontra em latitude de $21^{\circ} 15^{\prime} 22^{\prime \prime} \mathrm{S}$, longitude de $48^{\circ} 18^{\prime} 58^{\prime \prime} \mathrm{W}$ e altitude de $595 \mathrm{~m}$. O clima da região de Jaboticabal, baseado na classificação internacional de Köeppen, é do tipo Cwa: na época das águas predominam as chuvas de verão, com inverno relativamente seco.

O solo da área experimental foi classificado como Latossolo Vermelho eutrófico típico textura argilosa, apresentando topografia suavemente ondulada e condições de boa drenagem (Andrioli \& Centurion, 1999). A análise química da amostra composta de solo $(0-20 \mathrm{~cm})$ foi realizada pelo Departamento de Solos e 
Adubos da FCAV/UNESP. O solo apresentou $\mathrm{pH}$ 5,0 , com $17 \mathrm{~g} \mathrm{dm}^{-3}$ de matéria orgânica, $16 \mathrm{mg}$ $\mathrm{P} \mathrm{dm}^{-3}$ e 1,6, 14 e $9 \mathrm{mmol}_{\mathrm{c}} \mathrm{dm}^{-3}$ de $\mathrm{K}, \mathrm{Ca}$ e $\mathrm{Mg}$, respectivamente, resultando em uma porcentagem de saturação por bases (V\%) de 49.

Os experimentos foram instalados no sistema de semeadura convencional. O cultivar utilizado foi o IAC Runner 886. Para semeadura de ambos foram utilizados $125 \mathrm{~kg}$ de sementes por hectare, gerando uma deposição de 22 sementes por metro linear, com espaçamento de $0,90 \mathrm{~m}$, previamente tratadas com inseticida tiametoxan (Cruiser $700 \mathrm{WS}$ ).

Os tratamentos experimentais foram dispostos em duas áreas (dois experimentos): uma sem adubação e a outra área recebendo $150 \mathrm{~kg} \mathrm{ha}^{-1}$ do adubo formulado 00-20-20 no sulco de semeadura. Nos dois experimentos a cultura foi mantida sob interferência das plantas daninhas (convivência) por períodos iniciais crescentes desde a emergência do amendoim até $0,7,15,20,30,45,55$ e 126 dias (todo o ciclo da cultura), totalizando oito tratamentos experimentais. Entre os dois experimentos foi mantida uma distância de $2 \mathrm{~m}$ sem aplicação do adubo, para prevenir a contaminação entre eles.

O delineamento experimental foi o de blocos casualizados dentro de cada área, com os oito tratamentos em quatro repetições. Cada parcela foi constituída de quatro linhas de plantio (espaçadas de 0,90 m entre si) de $5 \mathrm{~m}$ de comprimento, totalizando $13,5 \mathrm{~m}^{2}$. A área útil para as avaliações compreendeu as duas linhas centrais.

Ao término de cada período de convivência das plantas daninhas com a cultura, foi realizado levantamento da comunidade infestante. A área total amostrada em cada parcela foi de $0,5 \mathrm{~m}^{2}$, composta por duas subamostras de 0 , $\mathrm{m}^{2}(0,5 \mathrm{~m} \times 0,5 \mathrm{~m})$, colhidas aleatoriamente na área útil da parcela. As partes aéreas das plantas daninhas encontradas nas duas subamostras foram coletadas e separadas, por espécie, determinando-se os valores de densidade e de massa seca de cada população. A massa seca da parte aérea das plantas daninhas foi obtida pela secagem em estufa com circulação forçada de ar a $70{ }^{\circ} \mathrm{C}$, até atingir massa constante. Após o término de cada período de convivência, foi realizado o controle das plantas daninhas nas parcelas correspondentes, que foram mantidas no limpo até a colheita por meio de capinas manuais.

Os dados de densidade e massa seca da comunidade infestante foram extrapolados para número de plantas e gramas de massa seca por metro quadrado, respectivamente; os de massa seca foram submetidos à análise de regressão. Com os dados obtidos em cada amostragem, foi realizada a análise fitossociológica da comunidade infestante, segundo procedimento descrito por Mueller-Dombois \& Ellemberg (1974), sendo determinada, para cada espécie, a dominância, a densidade e a frequência relativa; com esses dados, foi calculada a importância relativa. Para identificação e confirmação das espécies, recorreu-se à bibliografia especializada (Kissman $\&$ Groth, 2000; Lorenzi, 2000).

Para estimar a produção, o amendoim da área útil das parcelas foi pesado com casca (vagem), e os valores foram apresentados na forma comercial (sacas de $25 \mathrm{~kg}$ ).

Os resultados de produtividade de vagens foram submetidos à análise de regressão pelo modelo sigmoidal de Boltzmann, conforme utilizado por Kuva et al. (2001):

$$
Y=\frac{\left(A_{1}-A_{2}\right)}{1+e^{\left(x-x_{o}\right) / d x}}
$$

em que $Y$ é a produção de amendoim, obtida conforme os períodos de convivência; $X$, o limite superior do período de convivência considerado; $A_{1}$, a produção máxima obtida nas parcelas mantidas no limpo durante todo o ciclo; $A_{2}$, a produção mínima estimada decorrente das parcelas mantidas no mato durante todo o ciclo; $X_{o}$, o período superior do período de convivência, que corresponde ao valor intermediário entre a produção máxima e a mínima; e $d x$, o parâmetro que indica a velocidade de perda de produção (tangente no ponto $X_{\mathrm{o}}$ ).

Com base na equação de regressão, foi determinado o período anterior de interferência das plantas daninhas (PAI) para o nivel arbitrário de tolerância de 5\% de redução na produtividade, em relação ao tratamento mantido na ausência das plantas daninhas - nível este normalmente empregado em estudos dessa natureza. Na realização das análises de 
regressão foi utilizado o programa MicroCal Origin v. 8.0 (OriginalLab Corporation, USA).

\section{RESULTADOS E DISCUSSÃO}

Verificou-se que a comunidade infestante da faixa sem adubação foi composta por 20 espécies de plantas daninhas, pertencentes a 12 famílias, constatando-se boa diversidade de espécies (Tabela 1). Dentre elas, 14 foram eudicotiledôneas, correspondendo a $70 \%$ do total de espécies, e 30\% monocotiledôneas, com seis espécies. Dentre as monocotiledôneas, a família Poaceae foi a que apresentou maior número de espécies, e para as eudicotiledôneas foi a família Fabaceae.
Já na faixa adubada, a comunidade infestante foi composta por 22 espécies de plantas daninhas, pertencentes a 11 famílias, das quais $68 \%$ foram eudicotiledôneas e 32\% monocotiledôneas. Dentre estas, a família com maior número de espécies foi a Poaceae, com cinco, enquanto para as eudicotiledôneas foi Fabaceae, com quatro espécies (Tabela 1).

Nas duas faixas, o maior número de plantas daninhas foi de eudicotiledôneas, com 68 e $70 \%$ de representatividade para as faixas sem adubo e com adubo, respectivamente. A classe eudicotiledônea possui grande número de familias de plantas daninhas, sendo mais de 40 consideradas de importância econômica no Brasil (Deuber, 2003).

Tabela 1 - Plantas daninhas encontradas no levantamento fitossociológico nas áreas sem e com adubação (150 kg ha-1 do adubo 0-20-20). Jaboticabal-SP, 2007/2008

\begin{tabular}{|c|c|c|c|c|}
\hline Nome comum & Nome científico & Código* & $\begin{array}{c}\text { Área } \\
\text { adubada }\end{array}$ & $\begin{array}{l}\text { Área não } \\
\text { adubada }\end{array}$ \\
\hline Acanthosperum hispidum DC. & carrapicho-de-carneiro & ACNHI & $\mathrm{x}$ & $\mathrm{x}$ \\
\hline Amaranthus retroflexus L. & caruru & AMARE & $\mathrm{x}$ & $\mathrm{x}$ \\
\hline Amaranthus viridis $\mathrm{L}$. & caruru-de-mancha & AMAVI & $\mathrm{x}$ & \\
\hline Brachiaria plantaginea (Link) Hitchc. & capim-marmelada & BRAPL & & $\mathrm{x}$ \\
\hline Chamaesyce hirta (L.) Millsp. & erva-de-santa-luzia & EPHHI & $\mathrm{x}$ & $\mathrm{x}$ \\
\hline Chamaesyce hyssopifolia Small & erva-andorinha & EPHHS & & $\mathrm{x}$ \\
\hline Chamaecrista nictitans (Collad) H. S. Irwin \& Barneby & falsa-sensitiva & CASNI & $\mathrm{x}$ & $\mathrm{x}$ \\
\hline Commelina benghalensis $\mathrm{L}$. & trapoeraba & COMBE & $\mathrm{x}$ & $\mathrm{x}$ \\
\hline Cyperus rotundus $\mathrm{L}$. & tiririca & CYPRO & $\mathrm{x}$ & $\mathrm{x}$ \\
\hline Desmodium tortuosum (Sw.) DC. & pega-pega & DEDTO & $\mathrm{x}$ & $\mathrm{x}$ \\
\hline Digitaria sp. Wild & capim-colchão & DIGSS & $\mathrm{x}$ & $\mathrm{x}$ \\
\hline Echinochloa colonum L. & capim-arroz & ECHCG & $\mathrm{x}$ & $\mathrm{x}$ \\
\hline Eclipta alba (L.) Hassk & erva-botão & ECLAL & $\mathrm{x}$ & \\
\hline Eleusine indica (L.) Gaertn. & capim-pé-de-galinha & ELEIN & $\mathrm{x}$ & $\mathrm{x}$ \\
\hline Eragrostis pilosa (L.) P. Beauv. & capim-mimoso & ERAPI & $\mathrm{x}$ & \\
\hline Gomphrena celosioides Mart. & Perpétua & GOMCE & $\mathrm{x}$ & \\
\hline Indigofera hirsuta $\mathrm{L}$. & Anileira & INDHI & $\mathrm{x}$ & $\mathrm{x}$ \\
\hline Ipomoea grandifolia (Dammer) O'Donell & corda-de-viola & IAOGR & $\mathrm{x}$ & $\mathrm{x}$ \\
\hline Nicandra physaloides (L.) Pers. & joá-de-capote & $\mathrm{NICPH}$ & & $\mathrm{x}$ \\
\hline Panicum maximum Jacq. & capim-colonião & PANMA & $\mathrm{x}$ & \\
\hline Phyllanthus tenellus Roxb. & quebra-pedra & PYLNI & $\mathrm{x}$ & $\mathrm{x}$ \\
\hline Portulaca oleracea $\mathrm{L}$. & Beldroega & POROL & $\mathrm{x}$ & $\mathrm{x}$ \\
\hline Senna obtusifolia & Fedegoso & CASOB & $\mathrm{x}$ & $\mathrm{x}$ \\
\hline Sida rhombifolia $\mathrm{L}$. & Guanxuma & SIDRH & $\mathrm{x}$ & $\mathrm{x}$ \\
\hline Spermacoce latifolia Aubl. & erva-quente & BOILF & & $\mathrm{x}$ \\
\hline
\end{tabular}

* Código internacional, segundo International Weed Society; $\mathrm{x}=$ corresponde a ocorrência 
Dentre as monocotiledôneas, a família Poaceae foi a de maior representatividade. A classe monocotiledônea possui número reduzido de famílias de plantas daninhas importantes no Brasil, em torno de seis, destacandose principalmente a família Poaceae, com mais de 60 espécies (Deuber, 2003).

Analisando a densidade da comunidade infestante, em resposta aos períodos de convivência, para a faixa que não recebeu adubação, aos 15 dias após a emergência (DAE) da cultura a densidade da comunidade infestante atingiu valor máximo (144 plantas $\mathrm{m}^{-2}$ ), decrescendo aos 20 DAE (111,5 plantas $\left.\mathrm{m}^{-2}\right)$, tendo um novo fluxo aos $30 \mathrm{DAE}$, alcançando 125 plantas $\mathrm{m}^{-2}$, e decrescendo a partir dos $45 \mathrm{DAE}$, atingindo 31 plantas $\mathrm{m}^{-2}$ aos 126 DAE (Figura 1A). Na faixa que recebeu adubação, a densidade foi crescente até os 20 DAE, quando atingiu o máximo de indivíduos (100 plantas $\mathrm{m}^{-2}$ ), e manteve essa quantidade de indivíduos até os $30 \mathrm{DAE}$, decrescendo acentuadamente após esse período e chegando a 24 plantas $\mathrm{m}^{-2}$ aos 126 dias (Figura 1B). Bhan et al. (1971) e Agostinho et al. (2006) observaram que a maioria das plantas daninhas (acima de $75 \%$ ) emerge nos primeiros 30 DAE.

Com o desenvolvimento da comunidade infestante, o número de plantas por unidade de área diminuiu nas duas faixas. Essa redução na densidade populacional, segundo Pitelli (1987), pode ser atribuída a algumas plantas, que não suportaram a intensa competição interespecífica e morreram, como também algumas plantas de ciclo curto completaram seu ciclo antes das últimas avaliações. À medida que se aumenta a densidade e o desenvolvimento das plantas daninhas, especialmente daquelas que emergiram no início do ciclo de uma cultura, intensifica-se a competição inter e intraespecífica, de modo que as plantas daninhas mais altas e desenvolvidas tornam-se dominantes, ao passo que as menores são suprimidas ou morrem (Radosevich \& Holt, 1984).

$\mathrm{O}$ acúmulo de massa seca na parte aérea das plantas daninhas nas duas áreas (com e sem adubação) foi exponencial (Figura 2). A adubação foi realizada somente no sulco de semeadura e pode ter favorecido somente a cultura e não as plantas daninhas, explicando o comportamento semelhante para a comunidade infestante nas duas áreas, ou seja, a inexistência de efeito diferenciado da adubação.

As principais plantas daninhas que se destacaram durante o período de convivência nas parcelas foram as mesmas nas faixas com e sem adubação, pois apresentaram maior importância relativa (IR): tiririca (CYPRO), capim-pé-de-galinha (ELEIN), anileira (INDHI), beldroega (POROL) e guanxuma (SIDRH).

Observou-se que a tiririca teve maior importância relativa na faixa sem adubação: de 46 a 34\% aos 20 e 30 DAE, respectivamente,
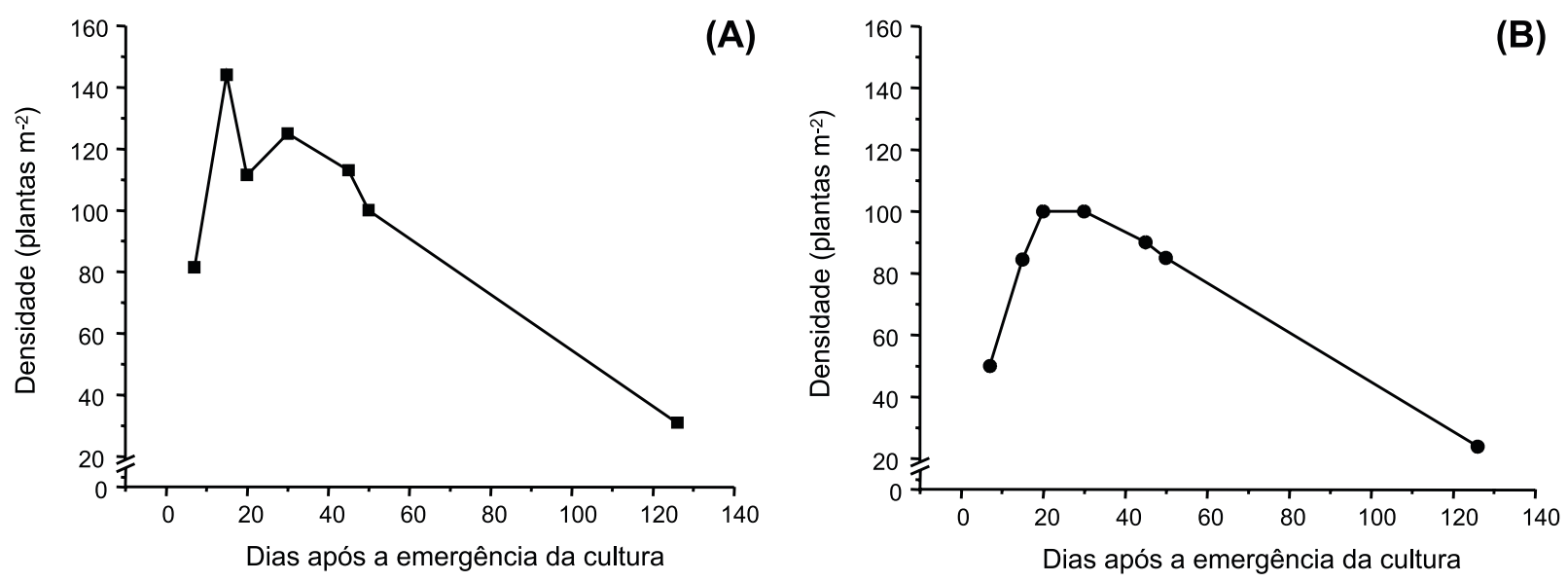

Figura 1 - Densidade da comunidade de plantas daninhas em função dos períodos de convivência com a cultura do amendoim (A) sem adubação e (B) com adubação (150 kg ha-1 do adubo 0-20-20). Jaboticabal-SP, 2007/2008. 

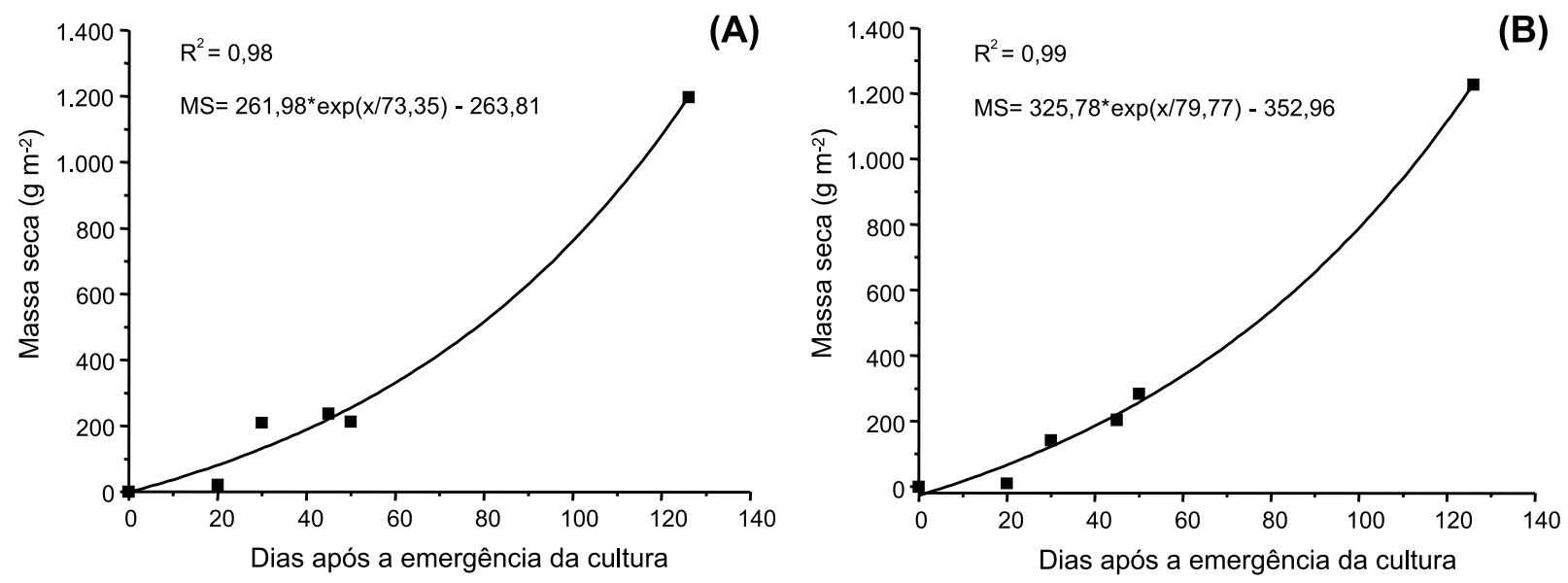

Figura 2 - Massa seca da parte aérea da comunidade de plantas daninhas em função dos períodos de convivência com a cultura do amendoim (A) sem adubação e (B) com adubação (150 kg ha'-1 do adubo 0-20-20). Jaboticabal-SP, 2007/2008

reduzindo para $19 \%$ aos 55 DAE. Isso pode ser explicado pela sua emergência antes do amendoim, com elevada brotação e crescimento vigoroso, devido às suas características e formas de reprodução. A redução ocorreu em decorrência da competição com outras espécies, sobretudo por luz, resultante do fechamento do dossel pela cultura, suprimindo o aparecimento dessa espécie por ocasião da colheita, uma vez que ela não tolera o sombreamento (Nemoto et al., 1995). Dos 40 aos 55 dias, a IR passou a ser maior para a beldroega, em torno de $25 \%$, porém na ocasião da colheita a espécie também não estava presente na área, devido ao encerramento do seu ciclo. Na colheita, a anileira, que até os 55 DAE se manteve com IR na faixa de $8 \%$, passou a ter a maior IR, atingindo $32 \%$, seguida do capim pé-de-galinha com $17 \%$ e guanxuma com 19\% (Figura 3).

Para a faixa adubada, observou-se que houve maior IR da tiririca seguida da beldroega até os $50 \mathrm{DAE}$; aos $126 \mathrm{DAE}$ também não se observaram plantas dessas espécies na área, quando a espécie mais importante foi a anileira, seguida de guanxuma e capim pé-degalinha, com 27, 19 e 9\% de IR, respectivamente (Figura 4).

Com relação à produtividade de vagens do amendoim, foi realizada a estimativa dos valores do limite superior do período anterior à interferência (PAI), em função de uma tolerância de redução de $5 \%$ na produtividade da cultura do amendoim. Tolerando-se essa redução na produção, o PAI da faixa sem adubação correspondeu a 17 DAE (Figura 5). Analisando a equação, verificou-se redução na produtividade de 128 para 88 sacas por hectare $\left(\mathrm{sc} \mathrm{ha}^{-1}\right)$ em relação àquelas que foram mantidas por todo o período no limpo, o que representa redução de $31 \%$.

Já para a faixa adubada, considerando tolerável uma perda de $5 \%$ na produtividade de vagens em decorrência da interferência

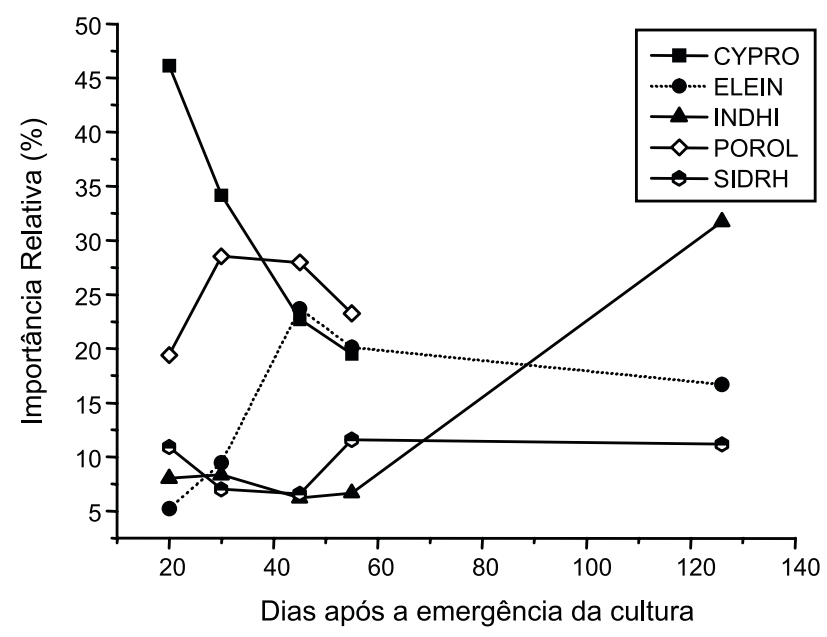

Figura 3 - Importância relativa de tiririca (CYPRO), capim-péde-galinha (ELEIN), anileira (INDHI), beldroega (POROL) e guanxuma (SIDH) em função dos períodos de convivência após a emergência do amendoim em uma área sem adubação. Jaboticabal-SP, 2007/2008. 


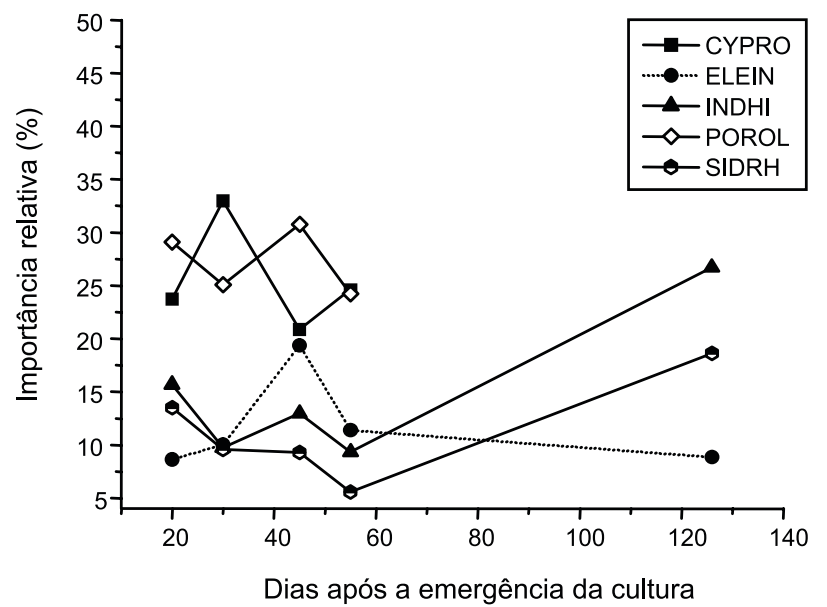

Figura 4 - Importância relativa de tiririca (CYPRO), capim-péde-galinha (ELEIN), anileira (INDHI), beldroega (POROL) e guanxuma (SIDRH) em função dos períodos de convivência após a emergência do amendoim em área com adubação (150 $\mathrm{kg} \mathrm{ha}^{-1}$ do adubo 0-20-20). Jaboticabal-SP, 2007/2008.

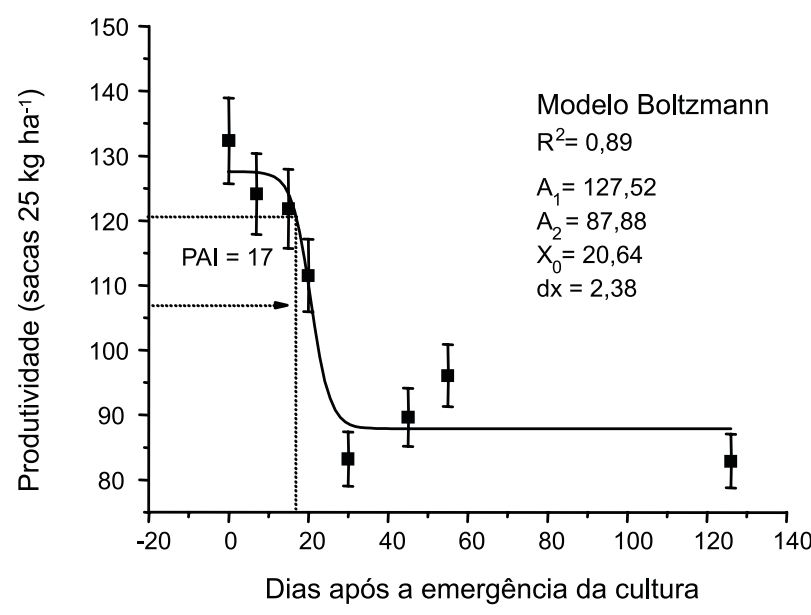

Figura 5 - Produtividade de vagens de amendoim sem adubação em função dos períodos de convivência. Jaboticabal-SP, 2007/2008

imposta pelas plantas daninhas, o PAI estimado segundo o modelo de Boltzmann foi de 15 DAE (Figura 6). Analisando a equação, verificou-se redução na produtividade de 138 para $92 \mathrm{sc} \mathrm{ha}^{-1}$ em relação àquelas que foram mantidas por todo o período no limpo, o que representa redução de 34\%.

O cultivar de amendoim, nas condições do experimento, evidenciou boa capacidade competitiva com ou sem adubação, pois, ao analisar os períodos em que a cultura permaneceu em convivência com as plantas daninhas durante todo o ciclo, verificou-se que houve redução média de cerca de $30 \%$ na produção. Comparando-se as reduções obtidas nas duas faixas de adubação com as obtidas em trabalhos anteriores, os valores obtidos foram inferiores, mesmo quando comparados com cultivares de porte rasteiro, cujas reduções variaram de 80 a 90\% (Agostinho et al., 2006; Nepomuceno et al., 2007; Dias et al., 2009). Esse resultado pode indicar maior tolerância do cultivar às plantas daninhas presentes na área, condicionada tanto pela composição especifica quanto pela densidade ou acúmulo de massa seca.

Analisando o PAI, verificou-se que a interferência se iniciou cedo para as duas faixas de adubação, aos 15 e $17 \mathrm{DAE}$, o que pode ser explicado pela alta infestação inicial das plantas daninhas na área. Esses resultados são semelhantes aos encontrados por Agostinho et al. (2006), que determinaram PAI de 6 e 14 DAE para os cultivares de porte rasteiro Runner Tégua e IAC Caiapó. Contudo, esses valores são inferiores se comparados aos obtidos em outros trabalhos com o cultivar IAC Runner 886, nos quais os valores de PAI variaram de 28 a 33 dias (Nepomuceno et al., 2007). Os resultados obtidos para este período são bastante variados, o que é normal, devido aos vários fatores que intervêm no grau de

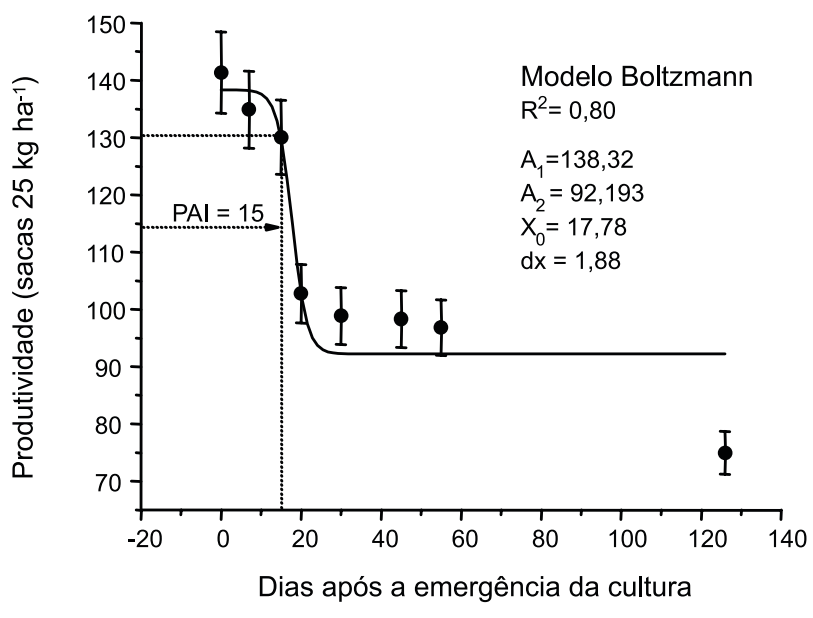

Figura 6 - Produtividade de vagens de amendoim com adubação (150 kg ha-1 do adubo 0-20-20) em função dos períodos de convivência. Jaboticabal-SP, 2007/2008. 
interação (Melo et al., 2001). A habilidade competitiva das plantas daninhas e das culturas é dependente das condições ambientais (Balbinot Jr. \& Fleck, 2005) e características das plantas, como estatura, cobertura do solo, taxa de crescimento relativa e propriedade alelopática, por exemplo.

Com base nos resultados, pode-se concluir que a adubação não alterou a composição da comunidade infestante. As espécies que apresentaram maior importância relativa foram Cyperus rotundus, Eleusine indica, Indigofera hirsuta, Portulaca oleraceae e Sida rhombifolia. A densidade das plantas daninhas foi maior na área não adubada, porém não houve diferença no acúmulo de massa seca entre as áreas. O cultivar de amendoim IAC Runner 886 pode conviver com essa comunidade infestante por até 15 e 17 dias após a emergência da cultura (PAI), na área com e sem adubação, respectivamente, sem sofrer perdas significativas na produção.

\section{LITERATURA CITADA}

AGOSTINHO, F. H. et al. Critical periods of weed control in peanuts. Peanut Sci., v. 33, n. 1, p. 29-35, 2006.

ANDRIOLI, I.; CENTURION, J. F. Levantamento detalhado dos solos da Faculdade de Ciências Agrárias e Veterinárias de Jaboticabal. In: CONGRESSO BRASILEIRO DE CIENNCIA DO SOLO, 27, 1999, Brasília. Anais... Brasília: Sociedade Brasileira de Ciência do Solo, 1999. 32 p. (T025-3 CD-ROM)

BALBINOT Jr., A. A.; FLECK, N. G. Competitividade de dois genótipos de milho (Zea mays) com plantas daninhas sob diferentes espaçamentos entre fileiras. Planta Daninha, v. 23 , n. 3 , p. $415-421,2005$.

BARBOSA, L. M.; PITELLI, R. A. Estudos sobre períodos de interferência de plantas daninhas na produtividade do amendoinzeiro (Arachis hypogaea L.). Hoehnea, v. 17, n. 1, p. $33-41,1990$

BHAN, V.; SINCH, M.; MAURYA, R. A. Crop weed competition studies in groundnuts. Indian J. Weeds Sci., v. 3 , n. 1, p. $32-36,1971$.

DEUBER, R. Ciência das plantas daninhas: fundamentos. 2.ed. Jaboticabal: FUNEP, 2003. v. 1. p. 134.

DIAS, T. C. S. et al. Efeito do espaçamento entre fileiras de amendoim rasteiro na interferência de plantas daninhas na cultura. Planta Daninha, v. 27, n. 2, p. 221-228, 2009.
ERASMO, E. A. L.; PINHEIRO, L. L. A.; COSTA, N. V. Levantamento fitossociológico das comunidade des plantas infestantes em áreas de produção de arroz irrigado cultivado sob diferentes sistemas de manejo. Planta Daninha, v. 22 , n. 2, p. 195-201, 2004.

EVERMAN, W. J. et al. Critical period of weed interference in peanut. Weed Technol., v. 22, n. 1, p. 63-67, 2008.

KASAI, F. S. et al. Efeitos dos períodos de competição do mato na cultura do amendoim: I. Safra da seca de 1988.

Bragantia, v. 56, n. 2, p. 323-331, 1997.

KISSMAN, K. G.; GROTH, D. Plantas infestantes e nocivas. 2.ed. São Paulo: Basf, 2000. 726 p.

KUVA, M. A. et al. Períodos de interferência das plantas daninhas na cultura da cana-de-açúcar. II - Capim-braquiária (Brachiaria decumbens). Planta Daninha, v. 19, n. 3, p. 323-330, 2001.

LORENZI, H. Manual de identificação e controle de plantas daninhas: plantio direto e convencional. 5.ed. Nova Odessa: Instituto Plantarum, 2000. 384 p.

MELO, H. B. et al. Interferência das plantas daninhas na cultura da soja cultivada em dois espaçamentos entre linhas. Planta Daninha, v. 19, n. 2, p. 187-191, 2001.

MESCHEDE, D. K. et al. Período anterior a interferência de plantas daninhas em soja: estudo de caso com baixo estande e testemunhas duplas. Planta Daninha, v. 22, n. 2, p. 239246, 2004.

MUELLER-DOMBOIS, D.; ELLEMBERG, H. Aims and methods of vegetation ecology. New York: John Willey \& Sons, 1974. 547 p

NAKAGAWA, J. et al. Densidade de plantas e produção de amendoim. Sci. Agric., v. 57, n. 1, p. 67-73, 2000.

NEMOTO, M. C. M. et al. Comportamento da tiririca (Cyperus rotundus) sob diferentes níveis de adubação fosfatada e de sombreamento. Planta Daninha, v. 13, n. 1, p. $50-55,1995$

NEPOMUCENO, M. P. et al. Efeito da época de semeadura nas relações de interferência entre uma comunidade infestante e a cultura do amendoim. Planta Daninha, v. 25, n. 3, p. $481-488,2007$.

PITELLI, R. A.; FERRAZ, E. C.; MARINIS, G. Efeito do período de matocompetição sobre a produtividade do amendoim (Arachis hypogaea L.). Planta Daninha, v. 4, n. 2, p. 110-119, 1981.

PITELLI, R. A. et al. Efeitos de períodos de convivência das plantas daninhas sobre a produtividade da cultura do amendoim das secas. Planta Daninha, v. 7, n. 1, p. 58-64, 1984. 
PITELLI, R. A. Interferência das plantas daninhas nas culturas agrícolas. Inf. Agropec., v. 11, n. 29, p. 16-27, 1985.

PITELLI, R. A. Competição e controle de plantas daninhas em áreas agrícolas. IPEF, v. 4, n. 12, p. 25-35, 1987

QUAGGIO, J. A.; GODOY, I. J. Amendoim. In: RAIJ, B. van et al. Recomendações de adubação e calagem para o Estado de São Paulo. 2.ed. Campinas: IAC, 1997. p. 194-195. (Boletim Técnico, 100).
RADOSEVICH, S. R.; HOLT, J. S. Weed ecology: implications for vegetation management. New York: John Wiley \& Sons, 1984. p. 263

RIZZARDI, M. A. et al. Competição por recursos do solo entre ervas daninhas e culturas. Ci. Rural, v. 31, n. 4 , p. 707-714, 2001.

RONCHI, C. P. et al. Acúmulo de nutrientes pelo cafeeiro sob interferência de plantas daninhas. Planta Daninha, v. 21, n. 2, p. 219-227, 2003. 